\title{
Autosomal dominant optic atrophy with asymptomatic peripheral neuropathy
}

\author{
R M Chalmers, A C Bird, A E Harding
}

\begin{abstract}
The association between hereditary motor and sensory neuropathy (HMSN) and optic atrophy has been termed HMSN type VI. The autosomal dominant inheritance of this syndrome is reported. Three generations were affected with optic atrophy, which differed in some respects from classic dominant optic atrophy, and an asymptomatic, mainly sensory, neuropathy.
\end{abstract}

$(\mathcal{F}$ Neurol Neurosurg Psychiatry 1996;60:195-196)

Keywords: hereditary motor and sensory neuropathy; optic atrophy; peripheral neuropathy

An association between optic atrophy and hereditary motor and sensory neuropathy (HMSN) was first described by Vizoli in 1889. ${ }^{1}$ Further examples have been described in families showing varied patterns of inheritance ${ }^{2-6}$ and in sporadic cases ${ }^{7-11}$ and the syn-

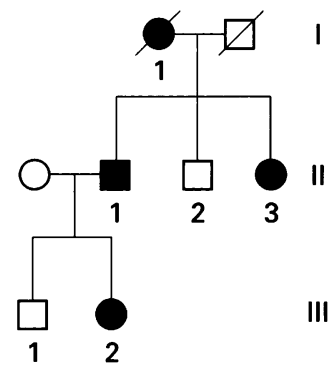

Pedigree of family. Solid symbols indicate affected members.

University Department of Clinical Neurology (Neurogenetics Section), Institute of Neurology, Queen Square, London, UK R M Chalmers A E Harding

Moorfields Eye Hospital, London, UK A C Bird

Correspondence to: Dr R M Chalmers, University Department of Clinical Neurology, Institute of Neurology, Queen Square of Neurology, Queen Square,
London WCiN 3BG, UK.

Received 8 August 1995 Accepted 27 September 1995 vibration sensation distally in the lower limbs. There was no muscle wasting or weakness. Hearing was normal. In the upper limbs motor conduction studies were normal, with median and radial sensory action potential (SAP) amplitudes of $13 \mu \mathrm{V}$ and $18 \mu \mathrm{V}$ respectively. In the legs tibial nerve muscle action potentials (MAPs) were normal, with a reduced MAP amplitude in the right peroneal $(3.6 \mathrm{mV}$ at the ankle recording from extensor digitorum brevis) and left peroneal nerves $(2.7 \mathrm{mV})$ without significant reduction in motor conduction velocities (MCVs) $(39-43 \mathrm{~m} / \mathrm{s})$. Sural and superficial peroneal SAP amplitudes were 1 $\mu \mathrm{V}$ and undetectable respectively. Needle EMG showed evidence of chronic partial denervation in distal muscles of both upper and lower limbs.

Her father (II-1), a 65 year old man, developed progressive visual problems from the age of 10 and by the age of 40 he was only able to perceive light. Examination at the age of 65 showed bilateral optic atrophy; there was no nystagmus. He was areflexic with impaired vibration sense distally in all limbs. There was no muscle wasting or weakness. Hearing was normal. In the upper limbs motor conduction studies were normal, but median and ulnar SAP amplitudes were $6.5 \mu \mathrm{V}$ and $2 \mu \mathrm{V}$ respectively. In the legs tibial nerve MCVs were normal; there was a reduction in MAP amplitude $(0.6 \mathrm{mV})$ and $\mathrm{MCV}(35 \mathrm{~m} / \mathrm{s})$ in the peroneal nerve. The sural SAP was small $(3 \mu \mathrm{V})$. Electromyography was normal.

The following family members were considered affected on the basis of history provided by relatives. Case I-1 developed progressive visual loss at the age of 10 and was only able to perceive light from the age of 30 ; case II- 3 , a 60 year old woman, developed optic atrophy at the age of 7 and was only able to perceive light from the age of 30 . Neither patient had any symptoms of muscle wasting, weakness, or impaired hearing.

\section{Discussion}

This family presented with optic atrophy and the autosomal dominant mode of inheritance is shown by the presence of both maternal and paternal transmission. None of the affected members had symptoms related to peripheral nerve disease but they had diminished tendon 
reflexes and impairment of sensation on examination. Nerve conduction and EMG confirmed the presence of an axonal sensorimotor neuropathy.

Two features are atypical for the classic form of dominant optic atrophy ("Kjer type") as defined by Smith. ${ }^{13}$ Firstly, the extent of visual loss - to perception of light only-is more severe than the moderately reduced visual acuity of $20 / 40$ to $20 / 400$ suggested by Smith ${ }^{13}$ and others. ${ }^{14}$ Secondly, this family has red-green dyschromatopsia and, while some report a range of colour defects, ${ }^{15}$ a blue-yellow colour defect is thought to be characteristic of dominant optic atrophy. ${ }^{13} 16$

The association of neuropathy and optic atrophy was first described in 1889 by Vizoli in a father and son; another son had neuropathy without optic atrophy. ${ }^{1}$ The only other reports in which autosomal dominant inheritance is possible is of a male with progressive optic atrophy and neuropathy, whose father had distal lower limb wasting but no visual symptoms. ${ }^{5}$ Autosomal recessive inheritance is likely in two further reports ${ }^{34}$ of affected siblings with normal parents (with parental consanguinity in one instance ${ }^{4}$. $\mathrm{X}$-linked recessive inheritance is proposed for the case of a grandfather with neuropathy and optic atrophy whose grandson had a neuropathy but no visual complaints. ${ }^{2}$ There have been some reports of sporadic cases of optic atrophy and neuropathy..$^{7-11}$

The classification of these reports is complicated by the need to differentiate progressive optic atrophy, as seen in classic "Kjer-type" optic atrophy, from other forms, such as Leber's hereditary optic atrophy (LHON). Four of the reported patients, with subacute visual loss, were young adult men, ${ }^{371011}$ suggestive of LHON. One family has been described in which LHON and HMSN segregate independently. ${ }^{6}$

Optic atrophy and neuropathy have also been found in association with other features. In particular, the triad of optic atrophy, neuropathy, and deafness has been described in autosomal dominant, ${ }^{17}$ recessive, ${ }^{18}$ and $\mathrm{X}$ linked recessive ${ }^{19}$ forms.

This report is the first clear description of autosomal dominant inheritance of progressive optic atrophy and neuropathy. The optic atrophy differed in some respects from classic dominant optic atrophy and the neuropathy was an asymptomatic, mainly sensory, axonal degeneration. The aetiology of these syndromes of optic atrophy and neuropathy is unknown. Recent evidence suggests that some families with dominant optic atrophy show linkage to markers on the telomeric portion of the long arm of chromosome $3 .^{20}$ Analysis of pedigrees with HMSN VI and other syndromes that include optic atrophy and neuropathy will determine whether they share a similar molecular basis.

Professor A E Harding died on 11 September 1995.

1 Vizioli F. Dell'atrofia progressiva nervosa. Bollettino della $R$ Accademia Medico-Chirurgica di Napoli 1889;1:173-83.

2 Sainton P. L'amyotrophie type Charcot-Marie. [MD Thesis] University of Paris, Paris, 1899.

3 Ballet G, Rose F. Un cas d'amyotrophie du type CharcotMarie avec atrophie des deux nerfs optiques. Rev Neurol 1904;12:522-4.

4 Schneider DE, Abeles MM. Charcot-Marie-Tooth disease with primary optic atrophy. Report of two cases occurwith primary optic atrophy. Report of two cases
ring in brothers. $\mathcal{F}$ Nerv Ment Dis $1937 ; 85: 541-7$.

5 Brihaye M, Nenquin-Klaassen E, Bertholet G. Atrophie musculaire neurogène du type Charcot-Marie-Toothmusculaire neurogene du type Charcot-Marie-ToothNeurologica et Psychiatrica Belgica 1956;56:302-12.

6 McLeod JG, Low PA, Morgan JA. A family with CharcotMarie-Tooth disease and Leber's optic atrophy Proceedings of the Australian Association for Neurology 1975;12:23-5.

7 Gordon A. Remarks on primary neurotic atrophy (CharcotMarie-Hoffman type) with report of a case in which there was excessive indulgence in tea and coffee. $\mathcal{F}$ Nerve Ment Dis 1903;30:354-9.

8 Krauss W. Atrophia nervi optici und neurotische Muskelatrophie. Zeitschrift für Augenheilkunde 1916;16: 503-16.

9 Piton J. L'amyotrophie Charcot-Marie. [MD Thesis] University of Paris, Paris, 1941.

10 Hoyt WF. Charcot-Marie-Tooth disease with primary optic atrophy. Report of a case. Arch Ophthalmol 1960,

11 Weiller C, Ferbert A. Hereditary motor and sensory neuropathy (HMSN) and optic atrophy (HMSN type VI Vizioli). Eur Arch Psychiatry Clin Neurosci 1991;240. 246-9.

12 Dyck PJ, Chance P, Lebo R, Carney JA. Hereditary moto and sensory neuropathies. In: Dyck PJ, Thomas PK, eds. Peripheral neuropathy. Philadelphia: Saunders, 1993. 1094-136.

13 Smith DP. Diagnostic criteria in dominantly inherited juvenile optic atrophy. A report of three new families. American fournal of Opthalmology 1972;49:183-200.

14 Eliott D, Traboulsi EI, Maumenee IH. Visual prognosis in autosomal dominant optic atrophy (Kjer type). $A m f$ Ophthalmol 1993;115:360-7.

15 Mäntyjärvi MI, Nerdrum K, Tuppurainen K. Color vision in dominant optic atrophy. $\mathcal{F}$ Clin Neuro-ophthalmol 1992; in dominan

16 Krill AE, Smith VC, Pokorny J. Similarities between congenital tritan defects and dominant optic-nerve atrophy: coincidence or identity? $\mathcal{F}$ Opt Soc Am 1970;60:1132-9.

17 Hagemoser K, Weinstein J, Bresnick G, Nellis R Kirkpatrick S, Pauli RM. Optic atrophy, hearing loss, and peripheral neuropathy. Am $\mathcal{F}$ Med Genet 1989;33: $61-5$.

18 Taylor J. Peroneal atrophy. Proc R Soc Med 1913;6:50.

19 Rosenberg RN, Chutorian A. Familial optoacoustic nerve degeneration and polyneuropathy. Neurology 1967;17: 827-32.

20 Eiberg H, Kjer B, Kjer P, Rosenberg T. Dominant optic atrophy (OPA1) mapped to chromosome $3 q$ region. I. Linkage analysis. Human Molecular Genetics 1994;3: Linkage 